\title{
Evidence for Differential Control of Posterior Hypothalamic, Supramammillary, and Medial Mammillary Theta-Related Cellular Discharge by Ascending and Descending Pathways
}

\author{
lan J. Kirk, Scott D. Oddie, Jan Konopacki, and Brian H. Bland \\ Department of Psychology, Behavioral Neuroscience Research Group, University of Calgary, Calgary, \\ Alberta, Canada T2N 1N4
}

\begin{abstract}
Single-unit discharge was recorded from cells in the posterior hypothalamic nucleus $(\mathrm{PH})$, supramammillary nucleus (SuM), and medial mammillary nucleus (MM) during hippocampal theta $(\theta)$ elicited by stimulation of the reticular nucleus pontis oralis (RPO). In agreement with previously published work, $\theta$-related cells in the $\mathrm{PH}(12$ cells) were all classified as tonic $\theta$-ON (increased tonic discharge rate during hippocampal $\theta$ ), whereas those in the SuM ( 9 cells) and MM (15 cells) were all classified as phasic $\theta-\mathrm{ON}$ (rhythmic discharge, in phase with ongoing $\theta$ ). The effect of RPO stimulation on cell discharge was tested after hippocampal $\theta$ was abolished by infusion of procaine into the medial septum/vertical limb of the diagonal band. The RPOelicited discharge patterns of all $\mathrm{PH}$ tonic $\theta-\mathrm{ON}$ cells and all SuM phasic $\theta-\mathrm{ON}$ cells survived septal procaine infusion. Fur-
\end{abstract}

ther, the discharge rate of $\mathrm{PH}$ cells and the frequency of burst discharge of SuM cells during RPO stimulation both increased after the infusion. In contrast, septal procaine infusion abolished the RPO-elicited rhythmic discharge pattern in MM phasic $\theta$-ON cells and attenuated their discharge rates. These results indicate that the $\mathrm{PH}$ and SuM form parts of an ascending system mediating hippocampal $\theta$, whereas the MM receives (and perhaps relays to other parts of the limbic system) rhythmic input descending from the septo-hippocampal system. In addition, $\mathrm{PH}$ and $\mathrm{SuM}$ receive descending inputs that limit the discharge rates of their $\theta$-related cells during hippocampal $\theta$.

Key words: intraseptal; procaine; hippocampal theta; supramammillary nucleus; posterior hypothalamic nucleus; medial mammillary nucleus; rhythmic cell discharge
Hippocampal theta $(\theta)$ activity is a large-amplitude, almost sinusoidal slow-wave activity, the occurrence of which has been postulated to be involved in processes of hippocampal synaptic plasticity (Pavlides et al., 1988; Buzsáki, 1989; Huerta and Lisman, 1993) and related behavioral functions (O'Keefe and Nadel, 1978; Bland et al., 1986; Miller, 1991). There is evidence that $\theta$ may be particularly important in hippocampal processing of spatial information (O'Keefe and Recce, 1993; Skaggs and McNaughton, 1996). It is well established that activation of an ascending system of projections that have their putative origin in the nucleus reticularis pontis oralis (RPO) elicits $\theta$ activity in the hippocampus (for review, see Vertes, 1986). These "synchronizing" effects are mediated via the medial septum/vertical limb of the diagonal band of Broca (MS/vDBB) (for review, see Bland, 1986; Stewart and Fox, 1990). However, there is a variety of recent evidence suggesting that, rather than directly influencing MS/vDBB activity, as had been proposed previously (O'Keefe and Nadel, 1978; Bland, 1986), reticular influences are relayed to the $\mathrm{MS} / \mathrm{vDBB}$ via a nuclei in the posterior hypothalamic region.

Anatomical work has suggested that fibers from the RPO are relayed to the MS/vDBB after first synapsing in the supramam-

\footnotetext{
Received April 18, 1996; revised June 5, 1996; accepted June 11, 1996.

This work was supported by Natural Sciences and Engineering Research Council (NSERC) Grant A9935 to B.H.B., a University of Calgary Post-Doctoral Fellowship to I.J.K., and an Alberta Heritage Foundation for Medical Research Post-Graduate Scholarship to S.D.O. J.K. was a visiting scientist supported by funds from NSERC. We thank Karen Waldie for comments on this manuscript.

Correspondence should be addressed to Brian H. Bland, Department of Psychology, Behavioral Neuroscience Research Group, The University of Calgary, Calgary, Alberta, Canada T2N 1N4.

Dr. Konopacki's current address: Department of Neurobiology, University of Lódź, 66 Rewolucji 1905r Street, 90-222 Lódź, Poland.

Copyright (C) 1996 Society for Neuroscience $0270-6474 / 96 / 165547-08 \$ 05.00 / 0$
}

millary nucleus (SuM) (Veazy et al., 1982; Vertes, 1982, 1992; Vertes and Martin, 1988). Procaine mapping of the system (Kirk and McNaughton, 1993) and rhythmic multiunit (Kirk and McNaughton, 1991) and single unit (Bland et al., 1993, 1995; Kirk et al., 1994; Kocsis and Vertes, 1994) activity in the SuM during $\theta$ suggest that, in addition to acting as a relay, the SuM transduces the intensity of RPO activity into the frequency of $\theta$.

Lesions of, or procaine infused into the region of, the posterior hypothalamus (PH) abolish hippocampal or septal $\theta$ activity (Kawamura et al., 1961; Anchel and Lindsley, 1972; Robinson and Whishaw, 1974; Bland et al., 1994, 1995; Oddie et al., 1994), and high-frequency $(100 \mathrm{~Hz})$ stimulation in the $\mathrm{PH}$ has been shown to be particularly effective in eliciting hippocampal $\theta$ field activity (Bland and Vanderwolf, 1972) and $\theta$ pattern discharge in medial septal cells (Bland et al., 1990). Thus, the PH has also been proposed to be a relay in the ascending synchronizing system. Further, there are dense projections from the posterior hypothalamic nucleus (PH) to the MS/vDBB (Vertes et al., 1993a). In contrast to SuM, however, $\theta$-related discharge in the $\mathrm{PH}$ is tonic (Bland et al., 1995).

Neurons in the mammillary nuclei have also been shown to discharge rhythmically at $\theta$ frequencies (Mignard et al., 1987; Kocsis and Vertes, 1994; Bland et al., 1995), and repetitive bursts have been recorded in vitro from the medial (MM) or lateral (LM) mammillary nucleus (Alonso and Llinás, 1992; Llinás and Alonso, 1992). As with hippocampal $\theta$, this activity in the mammillary nuclei may subserve their proposed role in memory in general (Mair et al., 1979), and spatial memory in particular (Sziklas and Petrides, 1993). In contrast to the SuM and PH, however, it has been suggested (although not unequivocally demonstrated) that the mammillary nuclei may receive $\theta$-frequency information de- 
scending from the septo-hippocampal system (Alonso and Llinás, 1992; Llinás and Alonso, 1992; Kocsis and Vertes, 1994). This information is likely of hippocampal origin (Kocsis and Vertes, 1994) and may be relayed to the mammillary bodies via the subiculum (Swanson and Cowan, 1975, 1977), i.e., via part of the circuit originally proposed by Papez (1937).

In the current experiments, $\theta$-related unit discharge was recorded from $\mathrm{PH}, \mathrm{SuM}$, and MM during hippocampal $\theta$ elicited by RPO stimulation (Vertes, 1982, 1986). Subsequently, hippocampal $\theta$ was abolished by septal infusion of procaine. Thus, the contribution of $\theta$-coded input descending from the septohippocampal system (relative to input ascending from the reticular formation) on the $\theta$-related unit discharge in the $\mathrm{PH}, \mathrm{SuM}$, and MM was determined.

\section{MATERIALS AND METHODS}

Thirty-four male Long-Evans rats $(0.25-0.5 \mathrm{~kg})$ were initially anesthetized with a mixture of Halothane (M.T.C. Pharmaceuticals, Cambridge, Ontario, Canada) in oxygen $(\sim 1.5 \%$ MAC) for jugular cannula insertion. Halothane was subsequently discontinued, and urethane $(0.8 \mathrm{gm} / \mathrm{ml})$ was administered via a jugular cannula as required for the remaining surgical and experimental procedures. Rats were secured in a stereotaxic apparatus, core temperature was maintained at $37^{\circ} \mathrm{C}$, and heart rates were monitored constantly throughout the experiments. Recording electrodes consisted of Kynar-insulated tungsten (etched to 0.5-1.0 $\mathrm{M} \Omega$ tip resistance) for hippocampal field activity, and glass electrodes (5.0-10 M $\Omega$ ) were filled with $0.5 \mathrm{~m}$ sodium acetate and $2 \%$ pontamine sky blue for unit recording. Bipolar stimulating electrodes consisted of two insulated stainless steel wires $(250 \mu \mathrm{m})$ twisted together. Glass electrode tip locations were marked by passing $50 \mu \mathrm{A}$ of current for $10 \mathrm{~min}(5 \mathrm{~min}$ cathodal, 5 min anodal). Procaine hydrochloride $[20 \%(\mathrm{w} / \mathrm{v})$ in saline, $2.0 \mu \mathrm{l}, 0.5$ $\mu \mathrm{l} / \mathrm{min}$ ] was infused into the $\mathrm{MS} / \mathrm{vDBB}$ region by a microinfusion pump via a $5 \mu \mathrm{l}$ Hamilton syringe connected to a 30 gauge cannula by SILASTIC tubing (Dow Corning, Midland, MI). Hippocampal recording electrodes were placed in the stratum moleculare of the dentate gyrus (AP, Bregma $-3.3 \mathrm{~mm}$; L, midline $2.4 \mathrm{~mm}$; DV, dura 2.5-3.0 mm). The tip of the infusion cannula was placed in the medial septum (AP, Bregma +0.0 to $0.5 \mathrm{~mm}$; L, midline $0.0 \mathrm{~mm}$; DV, 5.0 to $6.0 \mathrm{~mm}$ ). Glass unit recording electrodes were lowered through the $\mathrm{PH} / \mathrm{SuM} / \mathrm{MM}$ region (AP, Bregma -3.0 to $-5.0 \mathrm{~mm}$; L, midline $0.0-0.2 \mathrm{~mm} \mathrm{DV}$, dura $7.0-9.5 \mathrm{~mm}$ ) as described previously (Bland et al., 1995). Stimulating electrodes were placed in the RPO (AP, Bregma -8.0 to $-9.0 \mathrm{~mm}$; L, $1.0-1.5 \mathrm{~mm}$; DV, dura $8.0-9.0 \mathrm{~mm})$. After perfusion and fixation of the brain, frozen sections $(40 \mu \mathrm{m})$ were taken serially, mounted on glass slides, and stained with thionine for subsequent verification of hippocampal field electrode and septal cannula placement and glass electrode tip location.

Field and cell signals were stored on FM tape. Samples $(20 \mathrm{sec})$ of cell and field activity were taken during spontaneously occurring largeamplitude irregular field activity (LIA), and subsequently during $4-5 \mathrm{~Hz}$ $\theta$ field activity elicited by $100 \mathrm{~Hz}(100-300 \mu \mathrm{A})$ stimulation of the RPO. Sampling during RPO stimulation was from the onset of stimulation. In contrast to higher frequencies of stimulation-elicited $\theta(>6 \mathrm{~Hz})$ (Bland and Vanderwolf, 1972), intensities of RPO stimulation resulting in 4-5 $\mathrm{Hz} \theta$ resulted in a relatively stationary waveform over the $20 \mathrm{sec}$ sample. Samples (20 sec from stimulation onset) of field and cell activity were subsequently taken during the same level of RPO stimulation after hippocampal $\theta$ was abolished by infusing procaine $(2.0 \mu \mathrm{l})$ into the MS/vDBB region (Brücke et al., 1959; Mizumori et al., 1989; Kirk and McNaughton, 1993; Lawson and Bland, 1993). Cell discharge (spontaneous and stimulated every $2 \mathrm{~min}$ ) was sampled until hippocampal $\theta$ recovered.

Data analysis and separation of cell discharge from stimulation artifact was accomplished off-line using a PC microcomputer and a software acquisition and analysis package (DataWave Technologies, Longmount, CO). Unit cell activity was digitized through a 12 bit analog-to-digital converter and sampled at a frequency of $\sim 1.6 \mathrm{kHz}$. Field activity was simultaneously sampled at a frequency of $133 \mathrm{~Hz}$. Each data segment was subjected to a real-time fast Fourier analysis and classified as either $\theta$ or LIA by the following criteria: (1) $\theta$ was defined as a sinusoidal-like waveform with a peak frequency of 2-8 Hz and a small bandwidth, and (2) LIA was defined as a large-amplitude irregular activity with a broad frequency band $(0.5-25 \mathrm{~Hz})$ (see Leung et al., 1982). Analysis of digitized data samples provided the mean discharge rate of a cell (in $\mathrm{Hz}$ ) and an auto-correlation histogram $(\mathrm{ACH})$ of the discharge pattern of the cell. For cross-correlation analysis, both the digitized field activity and the spike train were converted to ASCII files and split into 512 bit $(3.85 \mathrm{sec})$ segments. Each spike train segment was convolved with a Gaussian kernel $[\delta=15 \mathrm{msec}$; the resulting spike density function (Ahmed and Rao, 1975; Richmond et al., 1987) reflected the interrather than the intraburst spike intervals] and cross-correlated relative to the hippocampal field activity using a frequency-domain algorithm (Press et al., 1986). Five segments were averaged to produce the final cross-correlation function $(\mathrm{CCF})$.

\section{RESULTS}

Cells localized to the PH, SuM, and MM were shown to have distinct $\theta$-related discharge patterns. The location of cells and examples of their discharge patterns (analog oscilloscope traces) in LIA and $\theta$ are shown in Figure 1. The relationship of the discharge of each type of cell to hippocampal EEG is shown in Figure 2. $\mathrm{PH}, \mathrm{SuM}$, and $\mathrm{MM}$ cells were classified in relation to hippocampal field activity according to criteria that have been used previously to classify cells in the hippocampal formation (Colom and Bland, 1987; Bland and Colom, 1989), the entorhinal cortex (Dickson et al., 1995), the MS/vDBB (Ford et al., 1989), and cingulate cortex (Colom et al., 1988). All $\theta$-related cells recorded in the $\mathrm{PH}(n=12)$ were found to be of the tonic $\theta-\mathrm{ON}$ type (i.e., they discharged tonically and at higher rates during hippocampal $\theta$ elicited by RPO stimulation than during LIA; see Figs. $1 B, 2 A)$. All $\theta$-related cells in the $\operatorname{SuM}(n=9)$ and $\operatorname{MM}(n=$ $15)$ were found to be of the phasic $\theta$-ON type (i.e., they discharge in rhythmic bursts phase-locked to concurrent hippocampal $\theta$ activity and nonrhythmically during LIA; see Figs. $1 B, 2 B, C)$.

\section{Effects of septal procaine infusion}

An illustrative example of the effect of septal procaine infusion on the discharge of a $\mathrm{PH}$ tonic $\theta-\mathrm{ON}$ cell is shown in Figure $3 A$. The mean of the responses (in terms of discharge rate) of all $\mathrm{PH}$ tonic $\theta$-ON cells to septal procaine infusion is shown in Figure $4 A$. In the preprocaine condition, hippocampal $\theta$ was elicited by RPO stimulation. The rate of $\mathrm{PH}$ tonic $\theta-\mathrm{ON}$ cell discharge increased relative to that during LIA (see Figs. $2 A, 3 A$, Pre-Procaine). In the period immediately after the procaine infusion, in which suppression of hippocampal $\theta$ was maximal, not only was $\mathrm{PH}$ tonic $\theta-\mathrm{ON}$ cell discharge still observed, but the same level of RPO stimulation significantly $\left(t_{(1,11)}=3.6 ; p<0.05\right.$; Scheffé post hoc pairwise comparison) increased their mean discharge rate relative to the preprocaine condition (Figs. 3A, 4A, Post-Procaine). This was particularly evident in the illustrated cell (Fig. 3A). After 10-20 min, RPO stimulation again elicited clear $\theta$ activity in the hippocampal field and the rate of tonic cell discharge under stimulation returned to preprocaine levels (Figs. 3A, 4A, Recovery).

An illustrative example of the response of an SuM phasic $\theta-\mathrm{ON}$ cell to septal procaine infusion is shown in Figure $3 B$. In the preprocaine condition, RPO stimulation elicits hippocampal $\theta$ and phase-locked rhythmical SuM cell discharge. After septal procaine infusion, hippocampal $\theta$ activity is abolished but RPO stimulation continued to elicit rhythmical activity in SuM phasic $\theta$-ON cells. This is evident from the ACF of the cell (Fig. $3 B$, Post-Procaine). Although SuM phasic $\theta$-ON cells survived septal procaine infusion, this manipulation was not without effect. As can be seen in the example in Figure $2 B$ (compare ACH pre- vs postprocaine) and from the means in Figure $4 B$ (pre- vs postprocaine), RPO stimulation postprocaine elicited a slightly higher burst frequency in SuM phasic $\theta$-ON cells than the same level of stimulation in the preprocaine condition. Although small, the increase was found to be significant $\left(t_{(1,8)}=5.1 ; p<0.001\right.$; Scheffé 


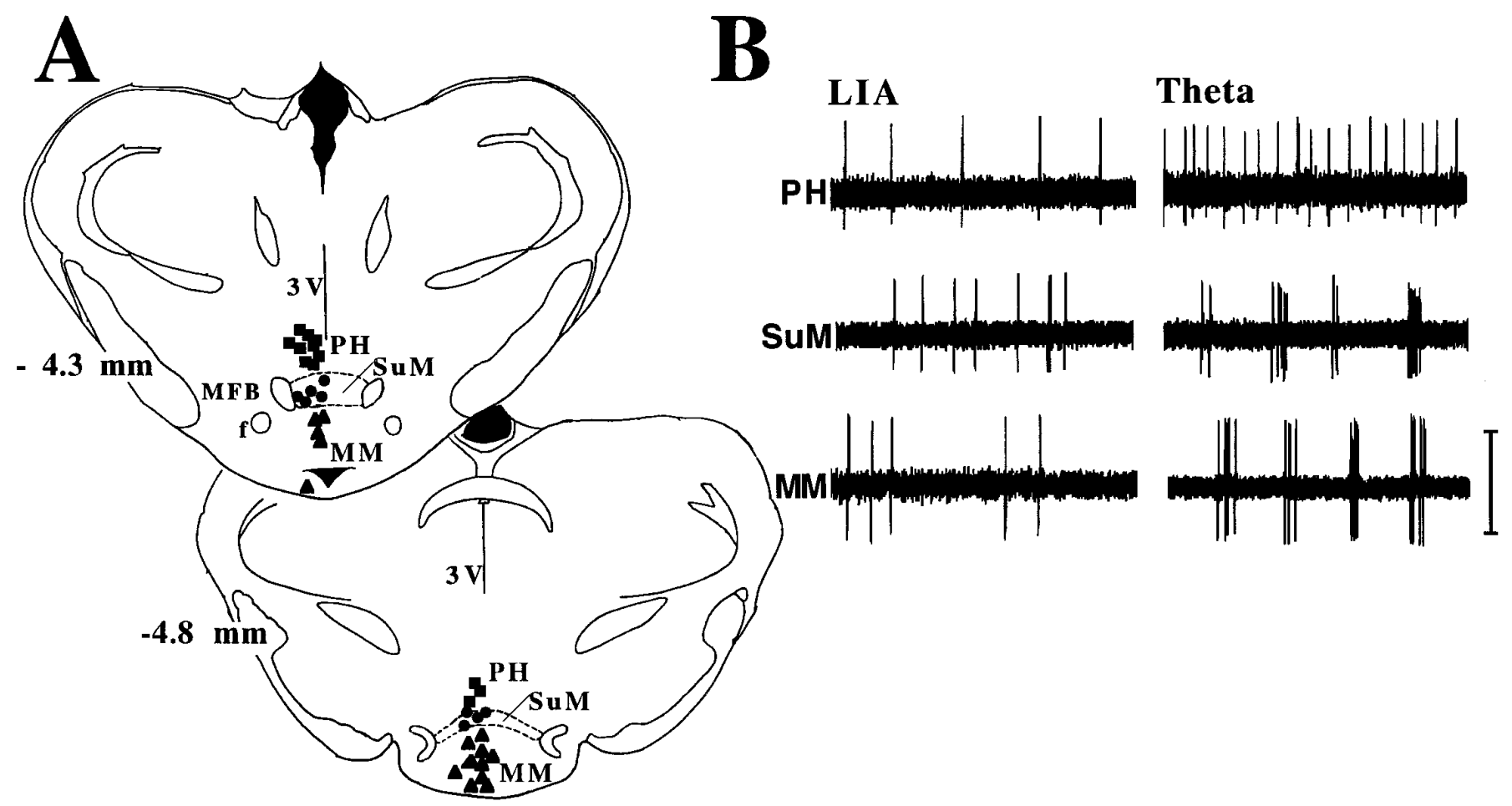

Figure 1. A, Diagrammatic reconstruction (Paxinos and Watson, 1982) of the location of classified cells in the caudal diencephalon. Cells were localized in the various nuclei by an examination of the histology showing pontamine sky blue deposits ejected from the glass microelectrodes used to record the cells. Tonic $\theta$-ON cells (shown as black squares) were found in the posterior hypothalamic nucleus $(P H)$, phasic $\theta$-ON cells were found in the supramammillary nucleus (SuM; black circles), and medial mammillary nucleus (MM; black triangles). B, Discharge patterns (1 sec oscilloscope traces) of $\mathrm{PH}$, SuM, and MM cells during spontaneous LIA (left side) and during theta elicited by RPO stimulation. Calibration bar, $0.5 \mathrm{mV}$.

post hoc pairwise comparison). After 10-20 min postprocaine, clear hippocampal $\theta$ was again elicited in response to RPO stimulation, and the frequency of burst discharge returned to preprocaine rates (Figs. 3B, 4B, Recovery).

The response of $\mathrm{MM}$ phasic $\theta-\mathrm{ON}$ cells to septal procaine infusion is illustrated in Figure $3 C$. As with the SuM phasic $\theta-\mathrm{ON}$ cells, in the preprocaine condition RPO stimulation elicits rhythmical $\mathrm{MM}$ cell discharge phase-locked to hippocampal $\theta$. In contrast to $\mathrm{PH}$ and SuM $\theta$-ON cells in which discharge rates but not discharge patterns were altered after septal procaine, septal procaine infusion radically altered the discharge rate and pattern in $\mathrm{MM}$ cells. As can be seen in Figures $3 C$ and $4 C$, in the first 5 min after septal procaine infusion (when the procaine block was maximally effective) MM cell discharge was severely attenuated (and in some cases abolished completely). This was the case for both spontaneous discharge and that during RPO stimulation. After the initial attenuation (or abolition) of MM cell discharge rates, spontaneous cell discharge rates increased toward preprocaine levels. However, RPO stimulation did not elicit rhythmical MM cell discharge patterns until clear $\theta$-activity was again observed in the hippocampal record.

\section{DISCUSSION}

In the present report, the dependence of $\theta$-related single-unit discharge of cells in the caudal hypothalamus on $\theta$ activity in the septo-hippocampal system was assessed. Hippocampal $\theta$ activity was elicited by RPO stimulation, and $\theta$-related discharge patterns of cells were classified according to previously used criteria. In accord with the findings of our previous study (Bland et al., 1995), $\theta$-related PH cells were all found to be of the tonic $\theta$-ON type (i.e., they discharged tonically and at higher rates during hippocampal $\theta$ than during LIA), whereas all $\theta$-related SuM and MM cells were of the phasic $\theta$-ON type (i.e., they discharge rhythmically and phase-locked to concurrent hippocampal $\theta$ activity, and nonrhythmically during LIA). Subsequently, the discharge patterns of the cells in response to RPO stimulation were tested after hippocampal $\theta$ was abolished by septal procaine infusion. It was found that $\theta$-related cells in different nuclei were differentially affected by the abolition of $\theta$.

The response of tonic PH $\theta-\mathrm{ON}$ cell discharge to RPO stimulation (i.e., increases in tonic discharge rate) survived after the abolition of $\theta$ by infusion of procaine into the septum. Furthermore, there was a significant increase in discharge rate during stimulation after procaine infusion relative to that during stimulation in the preprocaine condition. Similarly, rhythmic SuM phasic $\theta-\mathrm{ON}$ cell discharge in response to RPO stimulation was still observed after the abolition of hippocampal $\theta$ by septal procaine infusion. Again, however, septal procaine was not without effect. The burst frequency of SuM phasic $\theta$-on cells during stimulation after procaine was slightly (but significantly) higher than that seen during stimulation before procaine.

These data indicate that the increases in discharge rate of $\mathrm{PH}$ tonic $\theta$-ON cells and the rhythmic discharge of SuM phasic $\theta-\mathrm{ON}$ cells during hippocampal $\theta$ are independent of $\theta$ activity in the septo-hippocampal system. This supports previous suggestions that the $\mathrm{PH}$ and $\mathrm{SuM}$ are both relays in an ascending " $\theta$ synchronizing" system from the RPO to the MS/vDBB, and that $\mathrm{PH}$ tonic $\theta-\mathrm{ON}$ and SuM phasic $\theta-\mathrm{ON}$ cells act in synergy in the generation of hippocampal $\theta$. It has been suggested (Kirk and McNaughton, 1991, 1993) that the level of ascending tonic RPO input is transduced into the frequency of $\theta$ in the SuM (reflected 


\section{A) PH Tonic-ON Cell}
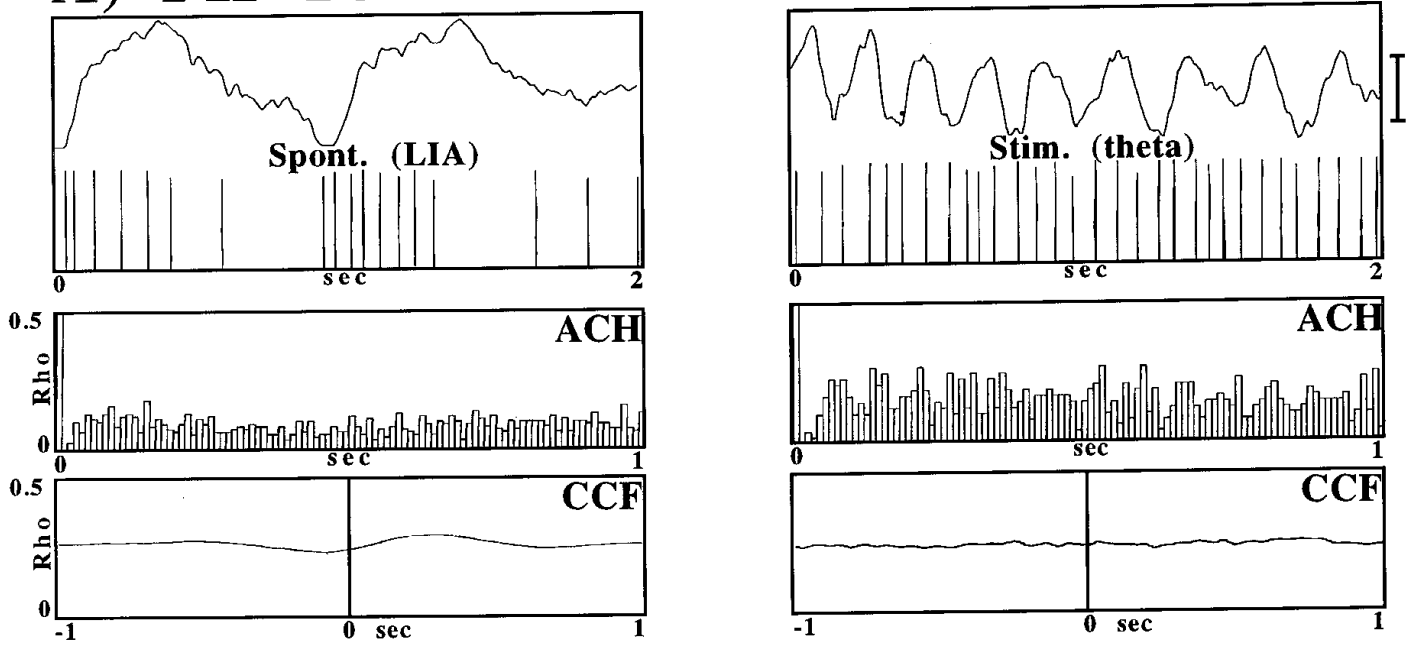

B) SuM Phasic-ON Cell
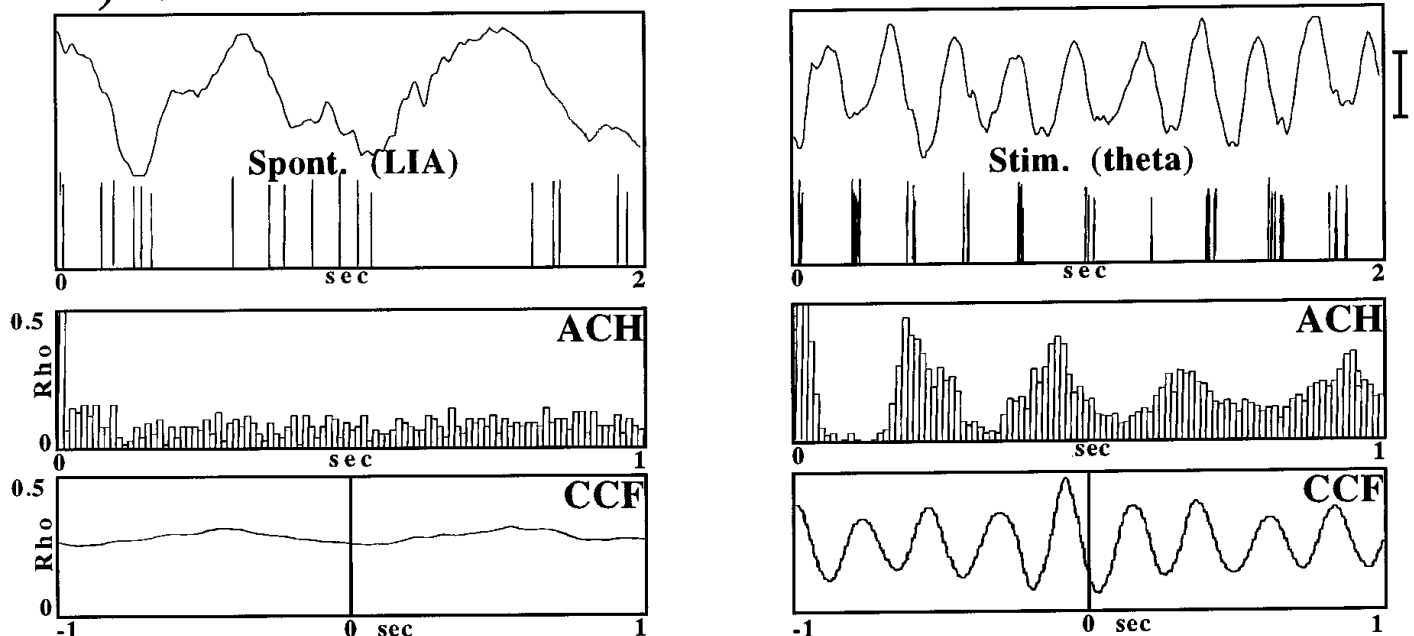

C) MM Phasic-ON Cell
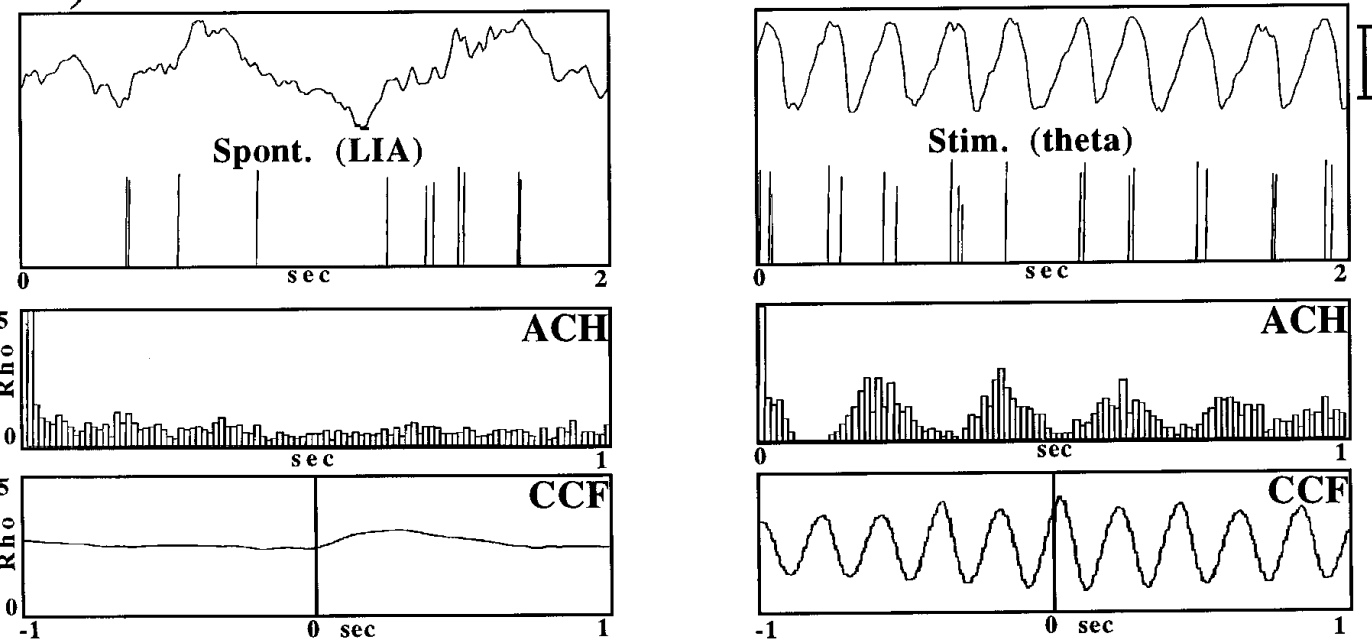

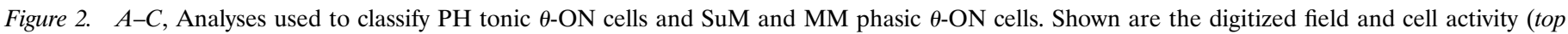

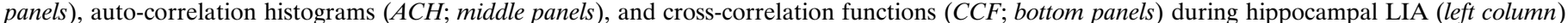

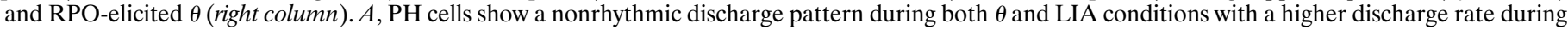

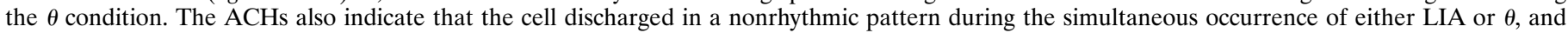

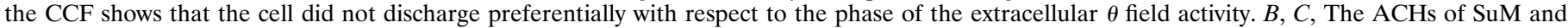

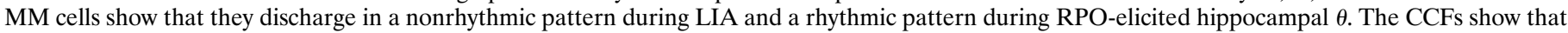
the cells discharged preferentially on a particular phase of the extracellular $\theta$ wave. Calibration bar, $1.0 \mathrm{mV}$. 


\section{A) PH Tonic-ON Cell}

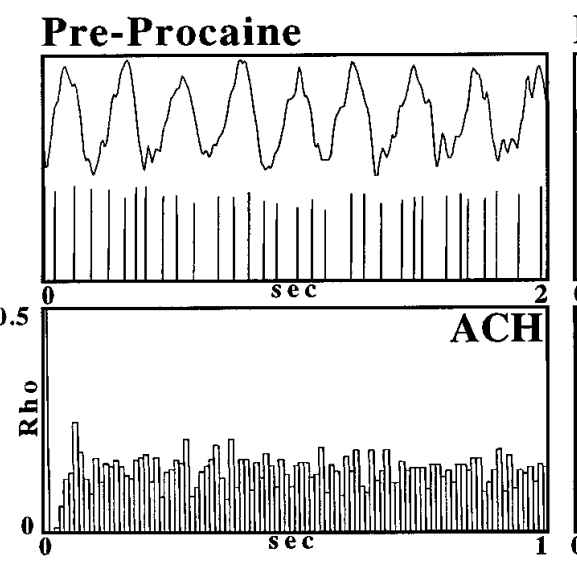

\section{Post-Procaine}

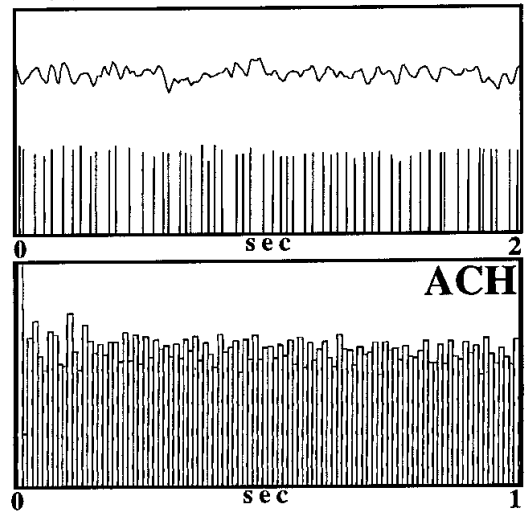

Recovery

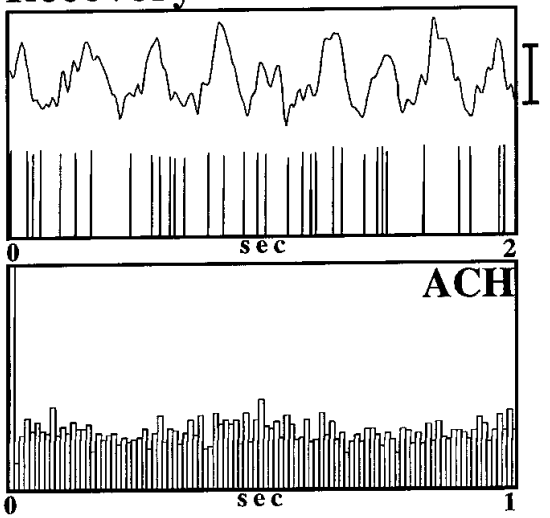

B) SuM Phasic-ON Cell

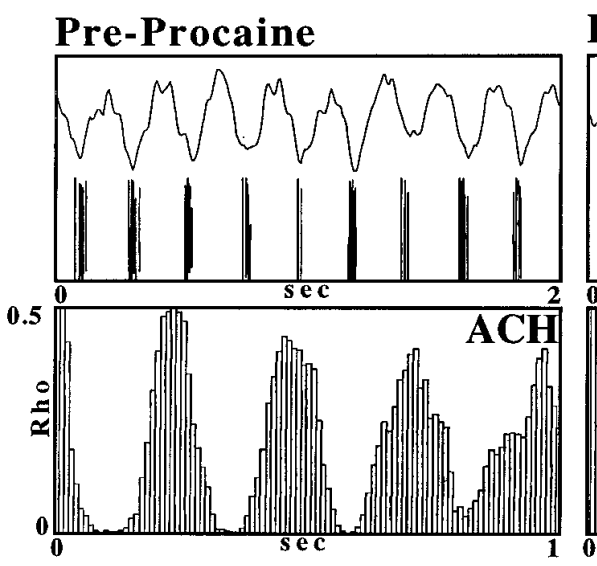

Post-Procaine

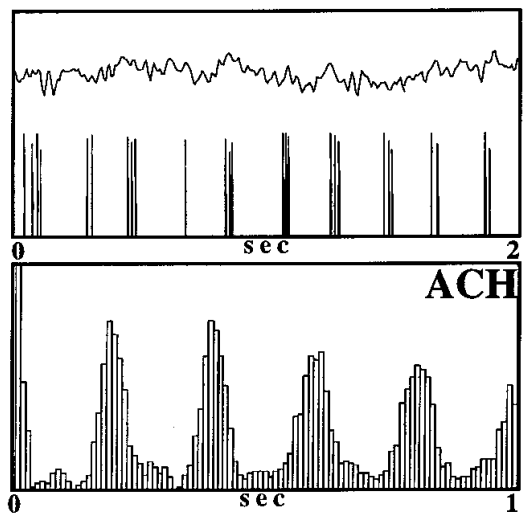

Recovery

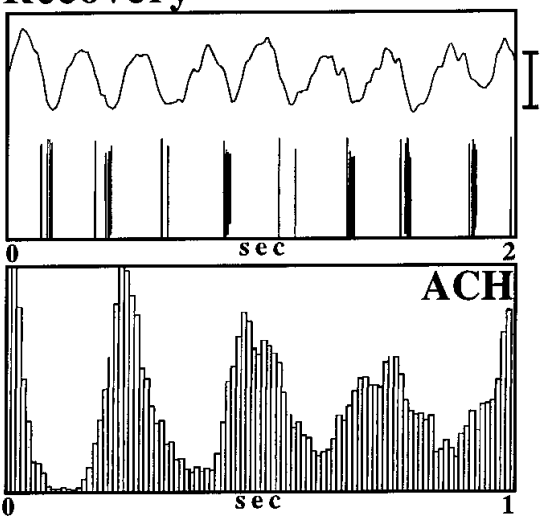

\section{C) MM Phasic-ON Cell}

\section{Pre-Procaine}

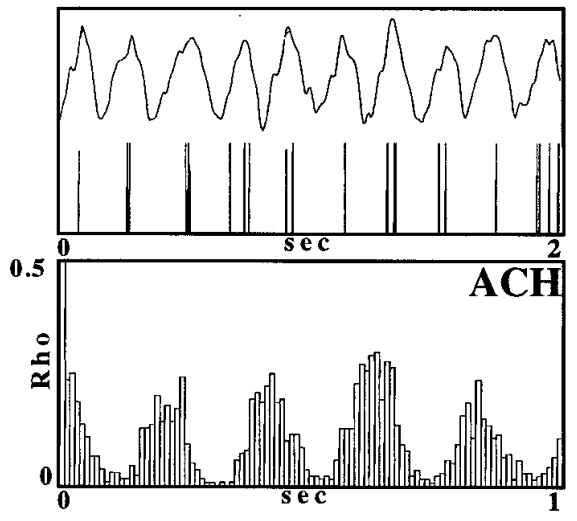

\section{Post-Procaine}
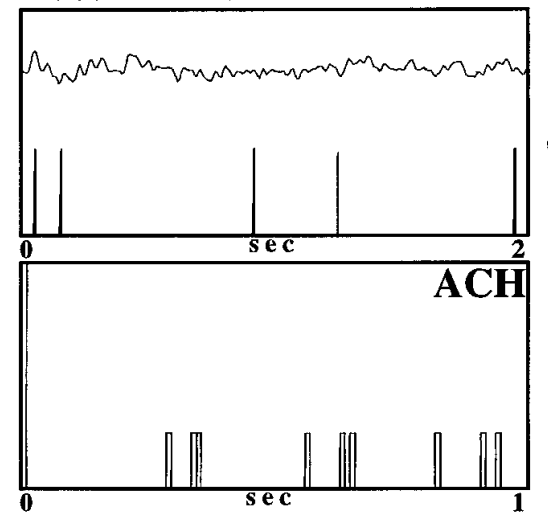

Recovery

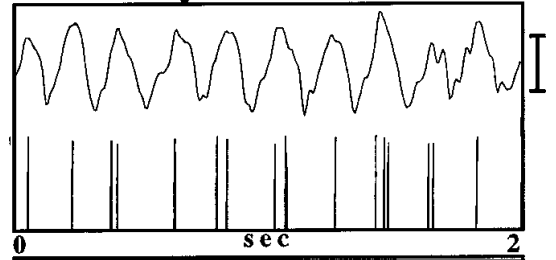

ACH

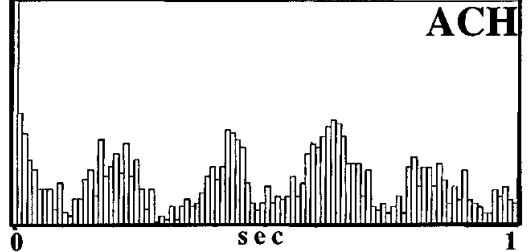

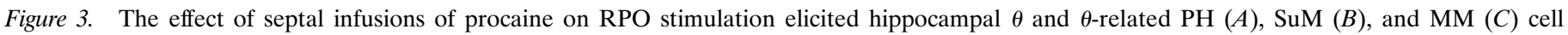

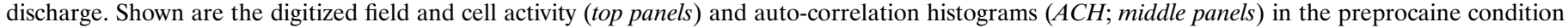

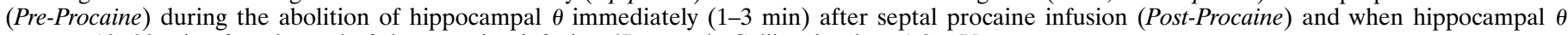
returns, 10-30 min after the end of the procaine infusion (Recovery). Calibration bar, $1.0 \mathrm{mV}$. 
A) $\mathrm{PH}$

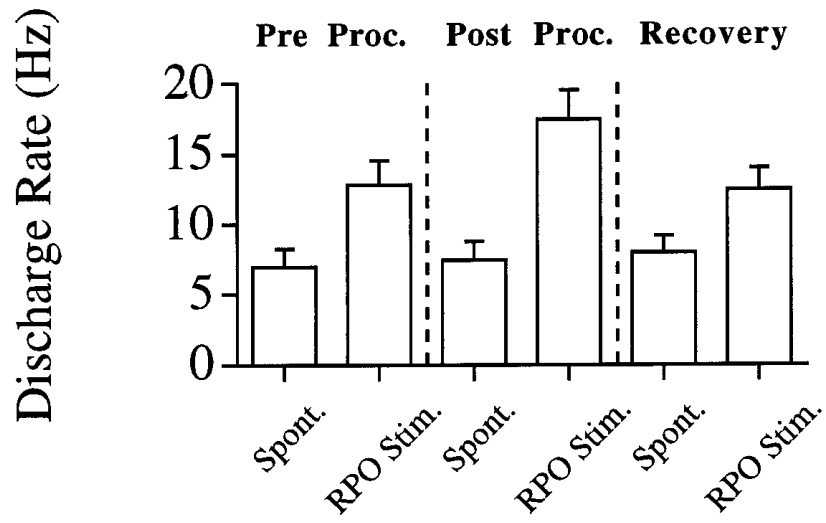

B ) SuM

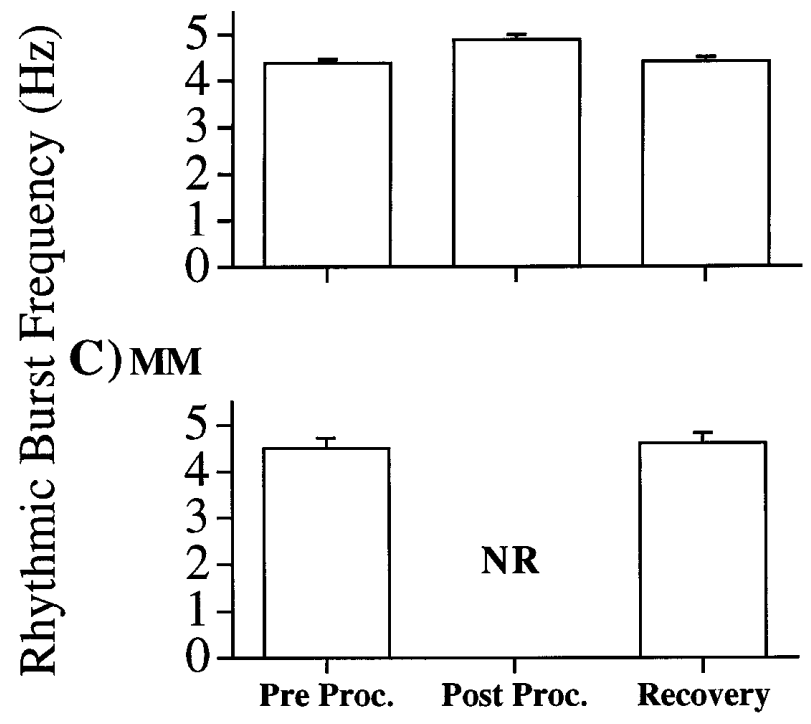

Figure 4. A, Mean discharge rate of PH cells (in the spontaneous condition and under RPO stimulation) before the septal infusion of procaine (Pre Proc.), within a 5 min period after the end of the septal procaine infusion in which RPO-elicited hippocampal $\theta$ was completely abolished (Post Proc.), and after RPO-elicited hippocampal $\theta$ had recovered to preprocaine levels (Recovery). Spontaneous levels of $\mathrm{PH}$ cell discharge were not significantly different across the preprocaine, postprocaine, and recovery conditions. Under RPO stimulation, however, significant differences in discharge rates were observed across conditions $\left(F_{(2,11)}=10.1\right.$; $p<0.005)$. The discharge rate of PH cells under RPO stimulation was significantly higher in the postprocaine condition relative to that in the preprocaine or recovery conditions (both $p<0.005$; Scheffé post hoc pairwise comparisons). $B$, Mean rhythmic burst frequency of SuM cells during RPO stimulation before the septal infusion of procaine (Pre Proc.), within a $5 \mathrm{~min}$ period after the end of the septal procaine infusion in which RPO-elicited hippocampal $\theta$ was completely abolished (Post Proc.), and after RPO-elicited hippocampal $\theta$ had recovered to preprocaine levels (Recovery). Significant differences in discharge rates were observed across conditions $\left(F_{(2,10)}=23.5 ; p<0.0005\right)$. The rhythmic burst frequency of SuM cells under RPO stimulation was significantly higher in the postprocaine condition relative to that in the preprocaine or recovery conditions (both $p<0.001$; Scheffé post hoc pairwise comparisons). $C$, Mean rhythmic burst frequency of MM cells during RPO stimulation before the septal infusion of procaine (Pre Proc.), within a $5 \mathrm{~min}$ period after the end of the septal procaine infusion in which RPO-elicited hippocampal $\theta$ was completely abolished (Post Proc.), and after RPO-elicited hippocampal $\theta$ had recovered to preprocaine levels (Recovery). There was no significant difference in rhythmic burst frequency between the preprocaine and recovery conditions. In the postprocaine period, rhythmic discharge was not observed $(N R)$. in the frequency of SuM cell burst discharge), and that this frequency-coded information is then fed via the medial forebrain bundle (Veazy et al., 1982; Vertes, 1992) to the MS/vDBB. The $\mathrm{PH}$, however, may provide tonic input (possibly cholinergic; see Brazhnik and Vinogradova, 1986; Oddie et al., 1994; Bland et al., $1995)$ to the MS/vDBB and hippocampus that accentuates rhythmic firing in septal cells (Brazhnik and Vinogradova, 1986; Bland et al., 1994) and is required for the expression of $\theta$ field activity in the hippocampus (Oddie et al., 1994).

The fact that after septal procaine infusion the rate of $\mathrm{PH}$ tonic $\theta$-ON cell discharge and the frequency of bursts of SuM phasic $\theta$-ON cells both increase during stimulation suggests that $\theta$-related $\mathrm{PH}$ and SuM cell discharge are normally subject to descending modulatory or rate-limiting influences from the septohippocampal system (on the basis of SuM multiunit activity after septal procaine, we have suggested previously that this may be true for the SuM (Kirk and McNaughton, 1991). Phasic $\theta-\mathrm{ON}$ cells in the SuM may also be involved in a mutual resonant interaction with those in the septo-hippocampal system during hippocampal $\theta$. This may result in phasic SuM cells being entrained to a lower burst frequency than would be the case if they were solely under the influence of input ascending from the midbrain. Miller (1991) has suggested previously an involvement of resonant loops in $\theta$ activity in other parts of the system (see also Bland and Colom, 1993).

Neither the origin nor the hypothalamic targets of the descending influence from the septo-hippocampal system are known. Because of diffusion (Myers, 1966), the volume of septal procaine infused $(2.0 \mu \mathrm{l})$ is likely to abolish or severely attenuate $\theta$-related discharge in a considerable region of the septal complex and, because of its dependence on septal projections, that in the hippocampus and parahippocampal areas as well (for review, see Miller, 1991). However, the lateral septum, which receives projections from hippocampal CA3 region (Swanson and Cowan, 1977; Leranth et al., 1992), sends descending projections to the SuM (Swanson and Cowan, 1979) and other diencephalic nuclei (Swanson and Cowan, 1979; Leranth et al., 1992). Thus, the lateral septal area may relay descending modulatory signals to $\mathrm{PH}$ and SuM during hippocampal $\theta$. As has been suggested previously, the descending influences may target a population of tonic $\theta$-OFF cells found in the border region between $\mathrm{PH}$ and SuM (Bland et al., 1995). It is also possible that the MM (in receipt of descending influences from the septo-hippocampal system, see below) mediates activity in $\mathrm{PH}$ and SuM. MM has been shown to project to surrounding hypothalamic regions including SuM and PH (Gonzalo-Ruiz et al., 1991). Clearly, more work is needed to distinguish between these possibilities.

It should be noted that whereas procaine infused into the SuM attenuated the amplitude and frequency of reticularly elicited hippocampal $\theta$ in urethane-anesthetized (Kirk and McNaughton, 1993; Thinschmidt et al., 1995) and unanesthetized (McNaughton et al., 1995) rats, lesions of the SuM did not appear to affect spontaneous and movement-related $\theta$ in the unanesthetized animal (Thinschmidt et al., 1995). It seems likely, therefore, that, as has been suggested previously, rhythmical activity in SuM is not necessary for the expression of $\theta$ per se (Kirk and McNaughton, 1993; Bland et al., 1995; Thinschmidt et al., 1995). Further, it has been demonstrated that lesions of the RPO produced little obvious change in hippocampal $\theta$ in freely moving animals (Farris and Sainsbury, 1990). Hence, it is possible that the SuM is involved in the modulation of $\theta$ frequencies only when in receipt of high levels of activation from the RPO that may normally only occur in 
particular behavioral states (Vertes, 1982, 1986) or, as in the present study, during RPO stimulation. Input from the $\mathrm{PH}$ may be particularly important for the expression of $\theta$ generally (see above). However, a variety of other pathways may be involved also. For example, cells of the pedunculopontine tegmentum (PPT) also project directly to the MS/vDBB (Woolf and Butcher, 1986), and stimulation of (Vertes, 1982), or infusion of carbachol into (Vertes et al., 1993b) the PPT has been shown to effectively elicit $\theta$.

In contrast to $\mathrm{PH}$ and $\mathrm{SuM} \theta-\mathrm{ON}$ cells, the discharge properties of $\mathrm{MM}$ phasic $\theta$-ON cells were considerably affected by septal procaine infusion. Not only was the discharge of MM phasic-ON cells nonrhythmic during RPO stimulation after septal procaine, but discharge rates were severely attenuated immediately after septal procaine infusion. The loss of rhythmic discharge of MM cells after septal procaine supports the results of partial coherence analysis suggesting that rhythmical, $\theta$-related MM discharge (but not that of SuM) is driven by descending inputs originating in the hippocampal formation (Kocsis and Vertes, 1994). As noted above, the MM is likely to receive descending input originating in the hippocampus and relayed via the subiculum (Swanson and Cowan, 1975, 1977; Allen and Hopkins, 1989). The MM projects heavily to the anterior thalamus (Veazy et al., 1982) and may be involved in relaying $\theta$-frequency activity from the septohippocampal system to the anterior nucleus of the thalamus (Alonso and Llinás, 1992). In turn, the anterior thalamus may relay, as Kocsis and Vertes (1994) note, $\theta$-frequency activity back to the hippocampus via the cingulate and entorhinal cortices. Thus, $\theta$ activity may be transmitted around the circuit originally described by Papez (1937). However, the MM is also in receipt of projections from the entorhinal cortex (Shibata, 1988) and medial septum (Swanson and Cowan, 1979).

The attenuation of MM discharge rates after septal procaine indicates that MM cell discharge per se is largely dependent on descending input from the septo-hippocampal system. During $\theta$-activity, descending input from the septo-hippocampal system may counteract inhibitory GABAergic influences to MM ascending from the midbrain (Tappaz and Brownstein, 1977; Stratford and Wirtshafter, 1989) or from the tuberomammillary nuclei (Gonzalo-Ruiz et al., 1992). MM cells in vitro (lacking extrinsic sources of modulation) can discharge in rhythmic (albeit sub- $\theta$ range) bursts (Alonso and Llinás, 1992). During $\theta$-activity in vivo, descending septo-hippocampal influences may act to overcome any tonic inhibitory input to $\mathrm{MM}$ and to entrain the endogenous rhythmic activity of MM cells to $\theta$ frequencies.

In summary, the single-unit work reported here has demonstrated that tonic $\theta$-ON cell discharge in $\mathrm{PH}$, and phasic $\theta$-ON cell discharge in SuM, is not dependent on input descending from the septum or hippocampus during $\theta$ activity. This supports the idea that the $\mathrm{PH}$ and SuM form relays in the ascending $\theta$-synchronizing system. The present study has also documented for the first time that MM phasic $\theta$-ON cell rhythmic discharge, and discharge per se, is largely dependent on input descending from the septohippocampal system during $\theta$. Finally, although descending input from the septo-hippocampal system to $\mathrm{PH}$ and $\mathrm{SuM}$ is not required for $\theta$-related activity in these structures, we provide evidence for descending, modulatory influences from the septohippocampal system to both $\mathrm{PH}$ and SuM.

\section{REFERENCES}

Ahmed N, Rao KR (1975) Orthogonal transforms for digital signal processing. Berlin: Springer.
Allen GV, Hopkins DA (1989) Mammillary body in the rat: topography and synaptology of projections from the subicular complex, prefrontal complex, and midbrain tegmentum. J Comp Neurol 286:311-336.

Alonso A, Llinás RR (1992) Electrophysiology of the mammillary complex in vitro. II. Medial mammillary neurons. J Neurophysiol 68:1321-1331.

Anchel H, Lindsley B (1972) Differentiation of two reticulohypothalamic systems regulating hippocampal activity. Electroenceph Clin Neurophysiol 32:209-226.

Bland BH (1986) The physiology and pharmacology of hippocampal formation theta rhythms. Prog Neurobiol 26:1-54.

Bland BH, Colom LV (1989) Preliminary observations on the physiology and pharmacology of hippocampal theta-off cells. Brain Res 505:333-336.

Bland BH, Colom LV (1993) Extrinsic and intrinsic properties underlying oscillation and synchrony in limbic cortex. Prog Neurobiol 41:157-208.

Bland BH, Vanderwolf CH (1972) Diencephalic and hippocampal mechanisms of motor activity in the rat: effects of posterior hypothalamic stimulation on behavior and hippocampal slow wave activity. Brain Res 43:67-88.

Bland BH, Colom LV, Ford RD (1990) Responses of septal $\theta$-on and $\theta$-off cells to activation of the dorsomedial-posterior hypothalamic region. Brain Res Bull 24:71-79.

Bland BH, Oddie SD, Dickson CT, Trepel C (1993) Discharge patterns of posterior-supramammillary hypothalamic cells in relation to hippocampal field activity. Soc Neurosci Abstr 19:355.

Bland BH, Oddie SD, Colom LV, Vertes RP (1994) The extrinsic modulation of medial septal cell discharges by the ascending brainstem hippocampal synchronizing pathway. Hippocampus 4:649-660.

Bland BH, Konopacki J, Kirk IJ, Oddie SD, Dickson CT (1995) Discharge patterns of hippocampal theta-related cells in the caudal diencephalon of the urethane anesthetized rat. J Neurophysiol 74:322-333.

Brazhnik ES, Vinogradova OS (1986) Control of the neuronal rhythmic bursts in the septal pacemaker of the theta rhythm: effects of anaesthetics and anticholinergic drugs. Brain Res 380:94-106.

Brücke F, Petsche H, Pillat B, Deisenhammer E (1959) Über veränderungen des hippocampus-elektrencephalogrammes beim kaninchen nach novocaininjektion in die septumregion. Arch Exp Pathol Pharmakol 273:276-284.

Buzsaki G (1989) Two-stage model of memory trace formation: a role for "noisy" brain states. Neuroscience 31:551-570.

Colom LV, Bland BH (1987) State-dependent spike train dynamics of hippocampal formation neurons: evidence for theta-on and theta-off cells. Brain Res 422:277-286.

Colom LV, Christie BR, Bland BH (1988) Cingulate cell discharge patterns related to hippocampal EEG and their modulation by muscarinic and nicotinic agents. Brain Res 460:329-338.

Dickson CT, Kirk IJ, Oddie SD, Bland BH (1995) The classification of theta-related cells in the entorhinal cortex: evidence that the ascending brainstem hippocampal synchronising pathway exerts parallel control of the EC theta cell discharges. Hippocampus 5:320-328.

Farris PD, Sainsbury RS (1990) The role of the pontis oralis in the generation of RSA activity in the hippocampus of the guinea pig. Physiol Behav 47:1193-1199.

Ford R, Colom LV, Bland BH (1989) The classification of medial septum-diagonal band cells as theta-on or theta-off in relation to hippocampal EEG states. Brain Res 493:269-282.

Gonzalo-Ruiz A, Alonso A, Sanz JM, Llinás RR (1991) Afferent projections to the mammillary complex of the rat, with special reference to those from surrounding hypothalamic regions. J Comp Neurol 321:277-299.

Huerta PT, Lisman JE (1993) Heightened synaptic plasticity of hippocampal CA1 neurons during a cholinergically induced rhythmic state. Nature 364:723-725.

Kawamura H, Nakamura Y, Tokizane T (1961) Effect of acute brain lesions on the electrical activities of the limbic system and neocortex. Jpn J Neurophysiol 11:564-575.

Kirk IJ, McNaughton N (1991) Supramammillary cell firing and hippocampal rhythmical slow activity. NeuroReport 2:723-725.

Kirk IJ, McNaughton N (1993) Mapping the differential effects of procaine on the frequency and amplitude of reticularly elicited rhythmical slow activity. Hippocampus 3:517-526.

Kirk IJ, Konopacki J, Bland BH (1994) Differential effects of septal procaine infusion on theta-related discharge patterns of posterior- 
hypothalamic, supramammillary, and medial mammillary neurons. Soc Neurosci Abstr 20:346.

Kocsis B, Vertes RP (1994) Characterization of neurons in the supramammillary nucleus and mammillary body that discharge rhythmically with the hippocampal theta rhythm in the rat. J Neurosci 14:7040-7052.

Lawson VH, Bland BH (1993) The role of the septohippocampal pathway in the regulation of hippocampal field activity and behavior: analysis by the intraseptal microinfusion of carbachol, atropine and procaine. Exp Neurol 120:132-144.

Leranth C, Deller T, Buzsáki G (1992) Intraseptal connections redefined: lack of a lateral septum to medial septum path. Brain Res 583:1-11.

Leung L-WS, Lopes da Silva FH, Wadman WJ (1982) Spectral characteristics of the hippocampal EEG in the freely moving rat. Electroenceph Clin Neurophysiol 54:303-319.

Llinás RR, Alonso A (1992) Electrophysiology of the mammillary complex in vitro. I. Tuberomammillary and lateral medial mammillary neurons. J Neurophysiol 68:1307-1320.

Mair WGP, Warrington EK, Weiskrantz L (1979) Memory disorder in Korsakoff's psychosis: a neuropathological and neuropsychological investigation of two cases. Brain 102:749-783.

McNaughton N, Logan B, Panickar KS, Kirk IJ, Pan W-X, Brown NT, Heenan A (1996) Contribution of synapses in the medial supramammillary nucleus to the frequency of hippocampal theta rhythm in freely moving rats. Hippocampus 5:534-545.

Mignard M, Bentzinger D, Bender N, Gabriel M (1987) Type I and type II theta-like unit activity in structures of the Papez circuit during differential avoidance conditioning in rabbits. Soc Neurosci Abstr 13:305.

Miller R (1991) Cortico-hippocampal interplay and the representation of contexts in the brain. Berlin: Springer.

Mizumori SYJ, Barns CA, McNaughton BL (1989) Reversible inactivation of the medial septum: selective effects on the spontaneous unit activity of different hippocampal cell types. Brain Res 500:99-106.

Myers RD (1966) Injection of solutions into cerebral tissue: relation between volume and diffusion. Physiol Behav 1:171-174.

Oddie SD, Bland BH, Colom LV, Vertes RP (1994) The midline posterior hypothalamic region comprises a critical part of the ascending brainstem hippocampal synchronizing pathway. Hippocampus 4:454-473.

O'Keefe J, Nadel L (1978) The hippocampus as a cognitive map. Oxford: Oxford UP.

O'Keefe J, Recce ML (1993) Phase relationship between hippocampal place units and the EEG theta rhythm. Hippocampus 3:317-330.

Papez JW (1937) A proposed mechanism of emotion. Arch Neurol Psychol 38:725-743.

Pavlides C, Greenstein YJ, Grudman M, Winson J (1988) Long-term potentiation in the dentate gyrus is induced preferentially on the positive phase of theta rhythm. Brain Res 439:383-387.

Paxinos G, Watson C (1982) The rat brain in stereotaxic coordinates. Sydney: Academic.

Press WH, Flannery BB, Teukolsky SA, Vetterling WT (1986) Numerical recipes: the art of scientific computing. Cambridge: Cambridge UP.

Richmond BJ, Optican LM, Podell M, Spitzer H (1987) Temporal encoding of two-dimensional patterns by single units in primate inferior temporal cortex. I. Response characteristics. J Neurophysiol 57:132-146.

Robinson TE, Whishaw IQ (1974) Effects of posterior hypothalamic lesions on voluntary behavior and electroencephalograms in the rat. J Comp Physiol Psychol 86:768-786.

Shibata HA (1988) A direct projection from the entorhinal cortex to the mammillary nuclei in the rat. Neurosci Lett 90:6-10.

Skaggs WE, McNaughton BL (1996) Replay of neuronal firing sequences in rat hippocampus during sleep following spatial experience. Science 271:1870-1873.

Statford TR, Wirtshafter D (1989) Gudden's tegmental nuclei are the major source of GABA found in the mammillary body of the rat. Soc Neurosci Abstr 2:1244.

Stewart M, Fox S (1990) Do septal neurons pace the hippocampal theta rhythm? Trends Neurosci 13:163-168.

Swanson LW, Cowan WM (1975) Hippocampo-hypothalamic connections: origin in subicular cortex not Ammon's horn. Science 189:303-304.

Swanson LW, Cowan WM (1977) An autoradiographic study of the organization of the efferent connections of the hippocampal formation in the rat. J Comp Neurol 172:49-84

Swanson LW, Cowan WM (1979) The connections of the septal region in the rat. J Comp Neurol 186:621-656.

Sziklas V, Petrides M (1993) Memory impairments following lesions of the mammillary region. Eur J Neurosci 5:525-540.

Tappaz ML, Brownstein MJ (1977) Origin of glutamate-decarboxylase (GAD)-containing cells in discrete hypothalamic nuclei. Brain Res 132:95-106.

Thinshmidt JS, Kinney GG, Kocsis B (1995) The supramammillary nucleus: is it necessary for the mediation of hippocampal theta rhythm? Neuroscience 67:301-312.

Veazy RB, Amaral DG, Cowan WM (1982) The morphology and connections of the posterior hypothalamus in the cynomolgus monkey (Macaca fascicularis). II. Efferent connections. J Comp Neurol 207:135-156.

Vertes RP (1982) Brainstem generation of hippocampal EEG. Prog Neurobiol 19:159-186.

Vertes RP (1986) Brainstem modulation of the hippocampus. In: The hippocampus, Vol 4 (Isaacson RL, Pribram KH, eds). New York: Pribram.

Vertes RP (1992) PHA-L analysis of projections from the supramammillary nucleus in the rat. J Comp Neurol 326:595-622.

Vertes RP, Martin GF (1988) Autoradiographic analysis of ascending projections from the pontine and mesencephalic reticular formation and the median raphe in the rat. J Comp Neurol 275:511-541.

Vertes RP, Crane AM, Colom LV, Bland BH (1993a) PHAL-L analysis of ascending projections from the posterior hypothalamus in the rat. Soc Neurosci Abstr 19:1442.

Vertes RP, Colom LV, Fortin WJ, Bland BH (1993b) Brainstem sites for the carbachol elicitation of the hippocampal theta rhythm in the rat. Exp Brain Res 96:419-429.

Woolf NJ, Butcher LL (1986) Cholinergic systems in the rat brain. III. Projections from the pontomesencephalic tegmentum to the thalamus, tectum, basal ganglia and basal forebrain. Brain Res Bull 16:603-637. 